\section{Entrepreneurial Orientation and Growth: The Moderating Role of National Culture}

\section{Dissanayake DM* and Semasinghe DM}

Center for Entrepreneurship Research and Development (CERD), Department of Commerce and Financial Management, Faculty of Commerce and Management Studies, University of Kelaniya, Sri Lanka

*Corresponding author: Dissanayake DM, Lecturer, Center for Entrepreneurship Research and Development (CERD), Department of Commerce and Financial Management, Faculty of Commerce and Management Studies, University of Kelaniya, Sri Lanka, Tel: +94 112 903903; E-mail: Neelacksha911@gmail.com

Received date: November 09, 2015, Archived date: January 20, 2016, Published date: January 26, 2016

Copyright: (c) 2016 Dissanayake DM, et al. This is an open-access article distributed under the terms of the Creative Commons Attribution License, which permits unrestricted use, distribution, and reproduction in any medium, provided the original author and source are credited.

\begin{abstract}
Complementing to the inferences of previous research, this paper seeks to investigate the moderating impact on the relationship of Entrepreneurial Orientation (EO) and venture growth. This study conducted as a cross sectional survey and utilized the sample frame of the registry of Small Enterprises Development Division, Sri Lanka. 317 entrepreneurs were captured from varied districts of Sri Lanka and the data were collected by means of a structured questionnaire. The assessment of the moderating effects was subjected to multi-group analysis and the moderation effect was observed in the Chi-Square difference test. Findings of the study revealed that, EO acts as a predictor of venture growth suggesting a direct positive relationship. EO-growth relationship is strengthening under a low power distant organization. Uncertainty and ambiguity an entrepreneur faces is also weaken the relationship of EO-growth. Finally, individualism weakens the relationship of EO-growth.
\end{abstract}

Keywords: Entrepreneurial orientation; Growth; National culture; Moderation

\section{Introduction}

Regardless of the type and the scale, all firms comprehend the value of growth. The notion of growth requires adding new ventures, proliferating the product portfolio and etc. But the theoretical inferences in this regard it, the literature is still fragmented Wiklund [1].

Despite the other facilitators of growth potentials, the presence of an entrepreneurial strategy is important. In the perspective of entrepreneurship, Entrepreneurial Orientation (EO) affirms the strategic view of the entrepreneur. Chirico et al. [2], wrote the notion of achieving the 'mobilizing vision of the firm' as a result of execution of EO. Others suggest, the strength of the relationship of EO and performance varies across contexts and studies Wales et al. [3]. Therefore, the emphasis on this paper is, though EO provides a vision to the firm in the perspective of strategy, the entrepreneur's willingness to implement the strategy is at least or partially depends on the innate cultural heritance of him/her. This premise has supported by empirical and conceptual evidences as well. Similarly, Saeed and Rauch et al. [4,5]. affirmed the need of moderation effects on the said relationship of EO and growth.

To achieve the mentioned objective of this research, the remainder of the paper is structured as follows. First the study laying out the pertaining theoretical foundations and derive the moderating hypothesis accordingly. Thereafter, the study proceeds to describe the methodological aspects employed in the paper. Finally, the paper proceeds to discuss the findings, implications, and presents some suggestions that required to be addressed in the future.

\section{Theoretical Background and Hypothesis}

Miller's [6], conceptualization of EO has been a seminal work of entrepreneurship and since then EO and performance relationship is addressed numerously in different contexts. It is subjected to contextual differences. The three sub-dimensional frameworks (innovativeness, proactiveness, and risk-taking) of $\mathrm{EO}$ of Miller was later extended by Lumpkin and Dess [7], and added two additional dimensions namely competitiveness aggressiveness and autonomy.

However, these dimensions of EO was derived from the scholarly contribution of Covin and Slevin et al. [8,9], innovativeness is the predisposition to engage in creativity and experimentation through the introduction of new products/services as well as technological leadership via $\mathrm{R}$ and $\mathrm{D}$ in new processes, while risk taking involves taking bold actions by venturing into the unknown, borrowing heavily, and committing significant resources to ventures in uncertain environments, proactiveness is an opportunity-seeking, forwardlooking perspective characterized by the introduction of new products and services ahead of the competition and acting in anticipation of future demand "autonomy refers to independent action undertaken by entrepreneurial leaders or teams directed at bringing about a new venture and seeing it to fruition" and competitive aggressiveness is the intensity of a firm's effort to outperform rivals and is characterized by a strong offensive posture or aggressive responses to competitive threats. However, Hughes and Morgan [10], wrote that Lumkin and Dess's framework is less examined in the literature.

In relation to EO and growth of firms, Moreno and Casillas [11], affirmed growth tends to be considered as a logical consequence of innovative, proactive and risk-taking behavior on the part of the firm, as these are the dimensions which define an EO, Thus the current study assumes EO as an antecedent of growth. The inconclusiveness of the relationship of EO and firm performance is depict from previous research remarks. For example, Zahra, Covin and Wiklund [12-15], suggested positive, and remarks such as Hughes, Morgan and Strong 
$[7,16]$, found exemptions on these findings. However, EO and growth relationship is not universally proven [17], also there are few number of studies have assessed EO and growth relationship Moreno and Casillas [11].

In the perspective of business performance, $\mathrm{EO}$ is a valuable construct which depicts the entrepreneurial strategy. It is rationale to state that venture growth is an important consideration which acquired through high performance. Thus, the researchers of the current study affirm that, if the entrepreneurial strategy (i.e., EO) is practiced in the firm besides the other considerations of venture growth, the values of expansion (i.e., growth) can be comprehended. With the objective facilitating the fragmented literature base of EO and growth, the following hypothesis is derived;

\section{$H_{1}$ : EO has a direct positive relationship on growth of firm.}

Though the literature is existing as fragmented, scholars view in this regard is EO and performance needs to be addressed with potential moderator effects $[7,4]$. Therefore, this research complements on their inferences.

Adhering to the notion of culture in the relationship of EO and growth is rationalized as follows in the current study. Still, the unchangeable notion of heart of entrepreneurship was proposed by Shane and Venkataraman [18], postulating the premise of opportunity recognition. But this study affirms that entrepreneur's willingness to assume entrepreneurial opportunities and to implement the entrepreneurial strategy in the venture successfully, his/her innate cultural background affects.

Therefore, it is assumed that there are cultural backgrounds hinders or stimulate people's willingness in entrepreneurial initiatives. Provided that, this study intends to address the remark, the strength of the relationship of EO and performance varies across contexts and studies Wales et al. [3], also the impetus of entrepreneurship in a country mostly lies within the individuals in that society and on degree of internal and external stimuli with regard to the spirit of enterprises. Provided that, a key question arises, what actually triggers entrepreneurship? Regardless of the diverse aspects of triggers of entrepreneurship, national culture and the relationship it has with the entrepreneurial activities are vital. Researchers of the current study put forth this point because, vested culture in a nation invariably on a link on how people think and behave. If so, one can determine that, culture shapes entrepreneurship. As mentioned above it may hinder of stimulate. According to Hayton et al. [19], understanding the importance and influence of national culture on entrepreneurship has both practical and theoretical value.

Assessment of the relationship between national culture and entrepreneurship persist for decades. But the phenomenon has assessed empirically Davidsson, Wiklund and Morris et al. [20-22]. However, it is important to state that the relationship between entrepreneurship and culture is not well established Hayton et al. [19].

The phenomenon of entrepreneurship appears to be more compatible with some cultures whereas with others do not to identify these differences Hofstede's [23], cultural dimensions would be a good starting point. Hofstede [23], in his seminal work on culture described a set of features that influences how group of people reacts to its environment and thus differentiates group membership. In his definition of national culture, independent dimensions were proposed in relation to national culture. Namely power distance, uncertainty avoidance, individualism, collectivism, masculinity and femininity. His discovery of national culture and the relational dimensions was a result of an employee attitude survey in the 1970's.

The survey was focused through a large scale research and data were collected at IBM. Basically the study's questions were related to values and it represented "mental programming of the respondent" [23]. Furthermore, Hofstede's identifications were, each person hold unique parts in relation to mental programming and those parts are shared with each other, however, some researchers criticized the Hofstede's work based on the fact that cultural dimensions of Hofstede do not adequately describes the differences in entrepreneurial activities in different countries Busenitz et al. [24], but many scholars agree Hofstede's work in the study of cultural values of entrepreneurship [19].

\section{First dimension}

Power distance it indicates the extent to which a society accepts the fact that power in institutions and organizations is distributed unequally [25], this notion also indicates the perception of organizational members who have less power in a country expect and accept the fact that, power has distributed unequally to the organizational structures with less power distance acknowledges the personal ability in decision making and vice versa. This implies the fact that organizational settings with less power distance often associates with the concepts of decentralization, less structured rules and regulations high degree of sharing information and authority. Highlighting the repercussions of high power distance, Van Everdingen and Waarts [26], postulated that being high power distance the adoption to new product ideas become low as high managerial positions do not identify operational problems and thus they rarely implements new product ides with less proactiveness.

Saeed et al. [4], suggested low power distance cultures facilitates reporting and connection with low and high organizational levels and it implies that the EO-performance relationship is strengthen in low power distant cultures. Further suggesting the degree of EO, implementation and commercialization of innovative ideas are constrained in high power distant cultures [27]. These previous scholarly remarks suggest that, when an organization is victimized by high power distant culture, performance of the venture restrained. Also effective implementation of EO in the process of growth is also constrained provided the high distance between employees and owners of the venture as low degrees of delegation of authorities are practiced. Therefore, the following hypothesis was derived in the study;

$H_{2 \mathrm{a}}:$ EO and entrepreneurial venture growth relationship is stronger in low power distant cultures.

\section{Second dimension}

Uncertainty avoidance "indicates the extent to which a society feels threatened by uncertain and ambiguous situations and tries to avoid these situations by providing greater career stability, establishing more suitable rules, not tolerating deviant ideas and behaviors, and believing in absolute truths and the attainment of expertise". Similarly, Kreiser et al. [28], asserted that, uncertainty avoidance depicts the degree to which the societal members feel with inherent ambiguities and threats. According to Hofstede the societies with high uncertainty avoidance tend to build standardized procedures, clear rules and structures, as they anticipate that those bring stability also people with low uncertainty avoidance are less resistant to change. 
Linking entrepreneurship, Van Everdingen and Waarts [26], wrote that, entrepreneurial firm's capacity to implement innovative products will be lower in high power distant contexts because buyers in such contexts often resist innovative products and the associated risks of those products. These implications imply the low levels of effectiveness of innovative products in a high uncertainty avoidance cultures and venture survival since innovativeness is one of the prime concerns for entrepreneurial firms. Supportively, Saeed et al. [4], highlighted that there is low degree of supplier switching in high uncertainty avoidance cultures. Therefore, this scenario implies that entrepreneurial firms will less likely to win customers though they adhere to the notion of innovativeness. They further postulated that the degree of formalization and bureaucracy is often associate with the uncertainty avoidance. It is important to note that organizations tend to formalize work routines provided the inherent ambiguity associate with the uncertainty avoidance and they believe that by formalizing work routines it brings stability. Similarly, Shane [29], affirmed that low uncertainty avoidance allow entrepreneurs to effectively implement entrepreneurial capabilities. Therefore, the current study complements $[4,29]$, and state that as high uncertainty avoidance and performance have a negative relationship, the uncertainty avoidance and growth relationship can be rationalized similarly. Therefore, the following hypothesis is realized.

$H_{2 \mathrm{~b}}$ : EO and entrepreneurial venture growth relationship is weaker in high uncertainty avoidance cultures.

\section{Third dimension}

Individualism vs. collectivism, the third dimension encompasses individualism and its opposite, Collectivism. Individualism implies a loosely knit social framework in which people are supposed to take care of themselves and of their immediate families only, while collectivism is characterized by a tight social framework in which people distinguish between in-groups and out-groups, they expect their in-group (relatives, clan, organizations) to look after them, and in exchange for that they feel they owe absolute loyalty to it Hofstede [23]. According to Kreiser et al. [28], this dimension defines independence of members in a society. Hofstede [25], wrote that people cultures which are characterized as collective (in-group collectivism) holds the characteristic of 'we' mentality whereas individual (low in-group collectivism) cultures holds the characteristic of 'I' mentality. Hofstede and Wedel [30], wrote that, low in-group collectivism creates and it stimulates innovativeness of a firm which results in high performance capability in a venture. Supporting Hofstede and Wedel, Van Everdingen and Waarts wrote that, collective cultures delay investments in innovations as collective decision are comparatively slower and thus affect to EO-performance relationship.

It is notable that collectivism and individualism is argued differently on the impact of EO-performance relationship. As pointed above, collectivism sometimes hinders EO-performance relationship. Opposing to Van Everdingen and Waarts, Saeed claimed that strong in-group collectivism supports effective implementation of EO than in low in-group collectivism. This inference has drawn as EOperformance relationship is strong within high in-group collective cultures. But their analysis partly supports the hypothesis. Provided the remarks of previous studies, the current study assumes that collective cultures stimulate EO's effective implementation of growth as a collective culture facilitate effective decisions though it is considered as slower process as Van Everdingen and Waarts suggested. Also it is assumed that collective cultures facilitate commercialization process as well.

$H_{2 c}$ : EO and entrepreneurial venture growth relationship is weaker in individual cultures.

\section{Fourth dimension}

Masculinity, Its opposite pole, femininity. "Measurements in terms of this dimension express the extent to which the dominant values in society are "masculine" that is, assertiveness, the acquisition of money and things, and not caring for others, the quality of life, or people". Hofstede wrote that, this dimension defines that women in general put an emphasis on social factors whereas men pay attention on ego goals like career and money. In particular, this distinction brings a question, how people are being motivated? Hofstede affirmed that, the notions of achievement and competition act as prime motivators of masculinity society, whereas, in feminine societies caring for others and quality of life are considered as motivators. Explaining the dimension further, Kreiser wrote that masculinity explains assertiveness and the level of self-confidence in a culture.

Saeed et al. [4], asserted the term 'economic calculations' which is known as a factor that becomes problematic when the economic value of an entrepreneurial activity cannot be examined fully and thus it prevents potential customers mainly in assertive cultures from taking products into attention. Supporting this premise, Hartog claimed that, in assertive cultures novelty in products and services can be stimulated as trust in business relationships is highly valued in such cultural settings. Furthermore, they highlighted that high levels of internal competition and lengthy meetings are the associate concepts of assertive cultures and thus it indicates that high assertive cultural settings hinders EO's performance. Empirically, Saeed found out EOperformance relationship gets weaken provided low level assertiveness though it was hypothesized EO-performance is stronger in low level assertive cultures. All in overall, the following hypothesis is realized.

$H_{2 \mathrm{~d}}: E O$ and entrepreneurial venture growth relationship is stronger in low assertive (masculine) cultures.

\section{Fifth dimension}

Long term vs. Short term orientation Hofstede [31], defined that countries or societies which depict long term orientations, usually associate with the principles of Confucianism, such as thrift and perseverance, respective traditional and family values, honoring of parents and offering financial aid to them are important concerns of long term orientation. Whereas, short term oriented societies expect the attributes of personal stability and steadiness, protecting one's face and etc. as mentioned above, countries favor for long term orientation prescribe the respect for the family and long term commitment. Provided that, business takes a long time to develop in a long term oriented context. According to Zahra et al. [32], short term oriented organizations favor short term financial gains over strategic goals. Therefore the current study assumes that short term orientation hinders entrepreneurial capabilities and thus growing potentials of a firm because being entrepreneurial requires long term directions and risk understandings. Supportively, Hitt wrote that success in entrepreneurship is achieved when a culture favor for patient investments in a long term. Also, Zahra [33], wrote that strategic controls supports entrepreneurship. All in overall, the study assumed that as strategic controls are determined for long term and those are 
created in a long term oriented environment, growth potentials are anticipated. Therefore, the following hypothesis is derived.

$H_{2 \mathrm{e}}$ : EO and entrepreneurial venture growth relationship is stronger in long term oriented cultures.

\section{Methodology}

\section{Sample and the sampling methodology}

The current study identifies the unit of the analysis as the firm and thus an entrepreneur is equated to the firm hereinafter. Also SME owner managers were also categorized as sample subjects in the current study. It is noted that SMEs are defined in varied ways imposing different operational definitions. Provided that the current study adheres to the operational definition of World Bank of Sri Lanka and captures SMEs below 99 employees. The sampling frame of the current study was taken from the registered SMEs under the District offices of the Small Enterprise Development Division, Ministry of Youth Affairs and Skill Development, Sri Lanka. Provided the varied contributions made by SMEs of each division to the Sri Lankan national economy Task Force for SME Sector Program [34], the disproportionate sampling method was proposed. Considering the contributions to the national economy, the significant districts were selected and the following table depicts the descriptive in relation to the sample. Personally administered questionnaires for pilot data collection was conducted in the month of July 2014 and subsequently main analysis was carried out within the period of August-December 2014 shown in Table 1.

\begin{tabular}{|l|l|l|l|}
\hline \# Interviewed & \# Responded & Response Rate & Final Sample \\
\hline 30 & 16 & $53.30 \%$ & 16 \\
\hline 33 & 30 & $90.90 \%$ & 30 \\
\hline 96 & 81 & $84.40 \%$ & 81 \\
\hline 28 & 25 & $89.30 \%$ & 25 \\
\hline 42 & 38 & $90.50 \%$ & 38 \\
\hline 180 & 143 & $79.40 \%$ & 143 \\
\hline $379 *$ & $317^{*}$ & $83.40 \%$ & $317^{*}$ \\
\hline *Excluding pilot data & \multicolumn{3}{|l}{} \\
\hline
\end{tabular}

Table 1: Response rates and distribution of the sample.

\section{Variables and measures}

Venture growth: In the entrepreneurship literature, measuring growth has confined to a limited number of indicators. However, the measurement approaches differ. These measurements include, for example, employee growth, sales, profit, equity, and etc. Meanwhile, Delmar [35], wrote the importance of employment and turnover rates as indicators of growth and Chandler et al. [36], wrote about sales growth and employee growth as indicators of growth. As mentioned above, the current study assumes venture growth as a proxy for firm performance [36-38]. The current study firmly affirms the fact that growth as a performance indicator of a firm depicts a complete picture as it is comparatively assessable and accurate than financial indicators of firm, provided the indicators available in the literature, the study brings a new indicator as Shepherd and Wiklund [39], suggested. They suggested the equity growth as the indicator holds a high validity.

Overall, the measurement of growth of the firm was assessed in a seven point likert scale as suggested by Wiklund et al. [39], According to their remarks, entrepreneurs were asked to rate the venture's growth potentials relative to their main competitors. The indicators used to construct the variable are, sales, competitors and equity growth. Afterwards, each indicators were standardized and summed into an index as Wiklund et al. claimed. The Cronbach's a for the venture growth index is 0.931

Entrepreneurial orientation: The current study acknowledges the seminal works of Miller and Lumpkin and Dess in relation to the EO construct. As suggested by Hughes and Morgan the current study employs the five dimensional framework of EO as it is considered as less examined. 18 content statements were assessed in a seven point likert scale and the dimensions assessed were, innovativeness, risk taking behavior, proactivenes, competitive aggressiveness and autonomy. The current study reported an acceptable level of reliability of Cronbach's $\alpha$ of 0.775 . Though this reliability level is perceived as relatively low, once Wiklund and Shepherd claimed 0.64 of Cronbach's a.

National culture: As reported above, the current study complements to the inferences of importantly, Rauch suggested the need of moderating impact on the relationship of EO and performance relationship. Therefore, the study brought Hofstede national cultural dimension to be assessed as Rauch suggested. This justification was also supported by Lee and Peterson. They stated that culture of a nation can either hinder or stimulate entrepreneurial behavior.

Therefore, the current study employed the Value Survey Model (VSM) of Hofstede and Minkov, in the VSM, 30 content questions were raised it has the capability to calculate six cultural dimensions. Also the claimed that, VSM is a 30 item questionnaire developed for comparing culturally influenced values of two similar respondents from two or more countries, or sometimes regions within countries. Cultural dimensions were assessed in a five point likert scale and indexes were created using the equations of VSM using SPSS syntax creator.

Control variable: Ventures in different industries exhibit different environmental characteristics which in turn influences growth potential. Therefore, the variable industry was used as controls in this study. To determine the industry which the venture categorizes, the respondents were asked to select their industry provided the classification of processing of rubber, tea, coconuts, tobacco, and other agricultural commodities, telecommunication, insurance, banking, tourism, shipping, clothing, textiles, cement, information technology services and constructions. In this study, the control variable of industry type falls outside the purview of the theoretical premises of the study and yet might affect growth of venture.

\section{Analysis and Methodology}

The current study employed two step procedures to achieve the objective of moderating impact of national cultural dimensions on the relationship of EO-growth. As suggested by Anderson and Gerbing [40], measurement model was assessed using Confirmatory Factor Analysis (CFA) followed by path relationships using Structural Equation Modelling (SEM). Maximum Likelihood (ML) estimation method was used using AMOS 18.0 version. The model fit was measured using incremental and absolute fit indices [41,42]. These 
Page 5 of 9

incremental model fit indices include, NFI, NNFI (TLI), CFI, PCLOSE, and and absolute model fit indices include Chi-Square $\chi^{2}$ (df, N)p, Relative $\chi^{2}\left(\chi^{2} / \mathrm{df}\right)$, RMSEA, GFI, AGFI, RMR, Hoelter (0.05). Cutoff values and acceptable threshold levels were observed in relation to these indices and optimum models were obtained and this adhered to the stages of model specification, identification, testing and modification [42]. After obtaining the modified model the study proceeded to analyze the moderating impacts. The study concerned the claim by James and Brett [43], and adhered to the fact that, the possibility of assessing variables functioning as a moderator, mediator or a hybrid, the overriding concern should be whether the hypothesized relationship has a theoretical support, highlighted the importance of multi-group analysis technique to measure moderating impacts. Provided the variable categories of continuous or discrete, James and Brett suggested by the need of rescaling continuous variables to discrete. Supportively, Frazier [44] wrote that, when the moderators are performed in a continuous scale the regression procedure to retain the continuous nature of the variable by splitting cutoff points (i.e., median splits). Wang [45], performed the relationship between EO, Learning Orientation, and firm performance using multi-group analysis as suggested by Joreskog et al. X2 was used to measure the statistical significance differences across groups. In this process, two models were executed, namely; constrained model and unconstrained model and subsequently the moderating impact was observed.

\section{Analysis and Results}

\section{Model validation}

The validation process of the current study adhered to the inferences of Kline [46] as the study follows SEM models. In this regard, model specification, identification and estimation, testing, model fit, and model modifications were performed to obtain the optimum model. Kline noted that the model specification requires specification of hypothesis in the form of structural model. Also, model identification refereed to theoretically justifiable models.

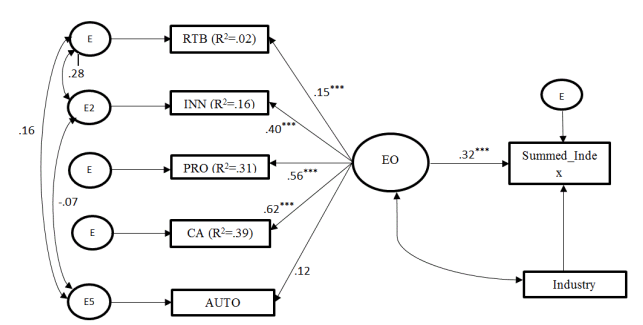

Figure 1: Standardized estimates of the modified model. Where; RTB: Risk Taking Behavior, INN: Innovativeness, PRO: Proactiveness, CA: Competitive Aggressiveness, AUTO: Autonomy, Summed_Index: Venture Growth; ${ }^{\star}$ Significant at $\mathrm{p}<0.01$ $* * *$ Significant at $\mathrm{p}<0.1$.

Therefore, the hypothesis of the current study were generated acknowledging the inferences mainly, therefore the model testing was performed and standardized estimates were observed and subsequently model fit was observed with incremental and absolute model fit indices were observed. Assessing model fit was followed by model modification and residual terms were covariated for the optimum model. Finally, the validated model was obtained shown in Figure 1.

The modifications led the model to be fitted optimally. This is evident by the model fit indices observed and those have depicted in the Table 2. As Brown [47], suggested acceptability of a model ensured by the model fit indices of RMSEA, CFI and TLI. The model indices were claimed as 0.06 or less, 0.95 or greater, and 0.95 or greater respectively. The current study's model indicated 'acceptable' model fit as per Brown.

\begin{tabular}{|c|c|c|c|}
\hline Indices & $\begin{array}{l}\text { Cutoff values } \\
\text { and } \\
\text { acceptable } \\
\text { threshold } \\
\text { levels }\end{array}$ & Initial model values & Decision \\
\hline \multicolumn{4}{|l|}{ Absolute Fit Indices } \\
\hline $\begin{array}{l}\text { Chi-Square } \\
X^{2}(\mathrm{df}, \mathrm{N}) \mathrm{p}\end{array}$ & $p>0.05$ & 0.289 & Satisfied \\
\hline Relative $x^{2}\left(x^{2} / \mathrm{df}\right)$ & $<3.00$ & $\begin{array}{l}\left(x^{2} / \mathrm{df}\right) \quad(7.352 / 6= \\
1.22)\end{array}$ & Satisfied \\
\hline RMSEA & $<0.07$ & 0.027 & Satisfied \\
\hline GFI & $>0.90$ & 0.992 & Satisfied \\
\hline AGFI & $>0.90$ & 0.974 & Satisfied \\
\hline RMR & $\begin{array}{l}\text { Lower then } \\
\text { better }\end{array}$ & 0.367 & Satisfied \\
\hline HOELTER (0.05) & $>200$ & 542 & Satisfied \\
\hline \multicolumn{4}{|c|}{ Incremental Fit Indices } \\
\hline $\mathrm{NFI}$ & $>0.90$ & 0.948 & Satisfied \\
\hline NNFI (TLI) & $>0.95$ & 0.973 & Satisfied \\
\hline CFI & $>0.95$ & 0.989 & Satisfied \\
\hline PCLOSE & $>0.50$ & 0.695 & Satisfied \\
\hline
\end{tabular}

Table 2: Absolute and incremental fit indices after altering the initial model.

\section{Results of the main hypothesis}

Once the model is satisfied as acceptable, the study proceeded to observe the derived hypothesis of the study. The model was tested with SEM and the moderations were tested by multi-group analysis Baron and Kenny [48], As suggested by James and Brett the continues nature of national cultural variables, were transformed into categorical and high and low groups were created accordingly. The categorization of two groups were based on the median splits. And constrained and unconstrained models were obtained in SEM and Chi-Square difference test was performed to measure the moderating impacts. 
Page 6 of 9

\begin{tabular}{|c|c|c|c|c|c|c|c|c|c|c|c|}
\hline \multirow[b]{2}{*}{ Relationship } & \multirow[b]{2}{*}{$\begin{array}{l}\text { Modera } \\
\text { tor }\end{array}$} & \multirow[b]{2}{*}{$\begin{array}{l}\text { Coeffici } \\
\text { ent }\end{array}$} & \multirow[b]{2}{*}{$\begin{array}{l}\text { Hypoth } \\
\text { esis }\end{array}$} & \multicolumn{2}{|c|}{ Chi-Square } & \multirow[b]{2}{*}{$\begin{array}{l}\text { Invaria } \\
\text { nt? }\end{array}$} & \multirow[b]{2}{*}{$\begin{array}{l}\text { Chi-Square (with } \\
\text { parameters estimated) }\end{array}$} & \multicolumn{3}{|c|}{ Chi-square Thresholds } & \multirow[b]{2}{*}{$\begin{array}{l}\text { Decisi } \\
\text { on }\end{array}$} \\
\hline & & & & $\begin{array}{l}\text { Unconstr } \\
\text { ained }\end{array}$ & $\begin{array}{l}\text { Fully } \\
\text { constraine } \\
\text { d }\end{array}$ & & & $\begin{array}{l}90 \% \\
\text { Confidenc } \\
\text { e }\end{array}$ & $\begin{array}{l}95 \% \\
\text { Confidenc } \\
\text { e }\end{array}$ & $\begin{array}{l}99 \% \\
\text { Confidenc } \\
\text { e }\end{array}$ & \\
\hline \multirow[t]{2}{*}{$\begin{array}{l}\text { EO - Venture } \\
\text { Growth }\end{array}$} & $\begin{array}{l}\text { High } \\
\text { PDI }\end{array}$ & $0.32^{\star \star \star}$ & \multirow[t]{2}{*}{$\mathrm{H}_{2} \mathrm{a}$} & \multirow[t]{2}{*}{27.869} & \multirow[t]{2}{*}{37.295} & \multirow[t]{2}{*}{ Yes } & \multirow[t]{2}{*}{34.535} & \multirow[t]{2}{*}{30.57} & \multirow[t]{2}{*}{31.71} & \multirow[t]{2}{*}{34.5} & \multirow[t]{2}{*}{ Accept } \\
\hline & Low PDI & $0.30^{\star \star \star}$ & & & & & & & & & \\
\hline \multirow[t]{2}{*}{$\begin{array}{l}\text { EO - Venture } \\
\text { Growth }\end{array}$} & $\begin{array}{l}\text { High } \\
\text { UAI }\end{array}$ & $0.32^{\star \star *}$ & \multirow[t]{2}{*}{$\mathrm{H}_{2} \mathrm{~b}$} & \multirow[t]{2}{*}{27.964} & \multirow[t]{2}{*}{42.344} & \multirow[t]{2}{*}{ Yes } & \multirow[t]{2}{*}{34.535} & \multirow[t]{2}{*}{30.67} & \multirow[t]{2}{*}{31.81} & \multirow[t]{2}{*}{34.6} & \multirow[t]{2}{*}{ Accept } \\
\hline & Low UAI & $0.32^{\star \star \star}$ & & & & & & & & & \\
\hline \multirow[t]{2}{*}{$\begin{array}{l}\text { EO - Venture } \\
\text { Growth }\end{array}$} & $\begin{array}{l}\text { High } \\
\text { IDV }\end{array}$ & $0.32^{* * *}$ & \multirow[t]{2}{*}{$\mathrm{H}_{2} \mathrm{C}$} & \multirow[t]{2}{*}{27.869} & \multirow[t]{2}{*}{37.295} & \multirow[t]{2}{*}{ Yes } & \multirow[t]{2}{*}{34.535} & \multirow[t]{2}{*}{30.57} & \multirow[t]{2}{*}{31.71} & 34.5 & Accept \\
\hline & Low IDV & $0.31^{\star * *}$ & & & & & & & & & \\
\hline $\begin{array}{l}\text { EO - Venture } \\
\text { Growth }\end{array}$ & $\begin{array}{l}\text { High } \\
\text { MAS }\end{array}$ & $0.30^{* * *}$ & $\mathrm{H}_{2} \mathrm{~d}$ & 30.279 & 31.806 & Yes & 30.547 & 32.9 & 34.12 & 36.91 & Reject \\
\hline & $\begin{array}{l}\text { Low } \\
\text { MAS }\end{array}$ & $0.31^{* \star *}$ & & & & & & & & & \\
\hline $\begin{array}{l}\text { EO - Venture } \\
\text { Growth }\end{array}$ & $\begin{array}{l}\text { High } \\
\text { LTO }\end{array}$ & $0.29^{\star \star \star *}$ & $\mathrm{H}_{2} \mathrm{e}$ & 35.762 & 40.4 & Yes & 35.784 & 38.47 & 39.6 & 42.4 & Reject \\
\hline & $\begin{array}{l}\text { Low } \\
\text { LTO }\end{array}$ & $0.31^{* * *}$ & & & & & & & & & \\
\hline
\end{tabular}

Table 3: Test of moderating effects.

\section{Discussion}

\section{Entrepreneurial orientation and growth}

It is important to recognize the fact that determination of EO as a predictor of performance (in this study performance was generalized as venture growth) is not indeed a novel contribution to the existing literature. However, that relationship was assessed as a contribution to the body of knowledge since some researchers have argued that the existence of gaps. Finally it was once more confirmed that EO acts as a significant predictor of venture growth under 1 percent level of significance. Importantly, the current study complemented on Hughes and Morgan's inference of autonomy as an insignificant dimension of EO. However, the $\mathrm{H}_{1}$ was accepted.

\section{Moderation effects of power distance}

As depicted in the section B of the shown in Table 3, it was hypothesized that the EO-growth relationship is weaken in high power distant cultures. The assessment of moderating effects were proceeded by splitting the sample into two groups provided the median of the power distant variable. The data above the median were categorized as high power distant and the data below the median as low power distant. Two models were ran and the first model's parameter to growth was constrained to be equal. And the second model was ran while fully constrained. Two Chi-Square values were obtained and entered to the Chi-Square difference excel sheet. The invariant nature of the model suggests that the model is not different across groups crated. But, the analysis suggested that the groups can be different in different Chi-Square thresholds and it suggests the need to run different path levels under different confidence levels. This different path levels are run by imposing constraints to the model. If the ChiSqaure value set to lie above the Chi-Sqaure threshold researchers can conclude that desired variable moderates the relationship of the constrained path under the desired confidence level. Provided that, the model was executed by imposing a constraint to the path of EO and Venture Growth which is the main relationship tested for the moderation. Under the imposed constrain the model was associated with the Chi-Square value of 34.535 which actually lies above the 99 percent Chi-Square threshold of 34.50. Based on that, researchers concluded that the model was moderated by PDI. The weakening or the strengthening nature was observed by the coefficient of the model. Coefficient in relation to high PDI was 0.32 and in low PDI 0.32 and thus the hypothesis $\mathrm{H}_{2 \mathrm{a}}$ was accepted.

\section{Moderation effect of uncertainty avoidance}

Same as the above cultural dimension, all the other cultural dimension were subjected to the same methodological consideration. Mentioning the hypothesis as EO and entrepreneurial venture growth relationship is weaker in high uncertainty avoidance cultures the researchers observed the path coefficient value prior to implement moderating and after moderating effect. Prior to implement the moderating effect the modified model was observed with the standardized beta value of 0.32 (between EO and growth). This implies the impact to the dependent variable of growth provided the one percent change of the predictor EO. The standardized beta estimate of 0.32 suggest a moderate to low level of impact (32 percent). However, 
after assessing the moderating effect of uncertainty avoidance the model was showed the same beta coefficient.

However, the fully constrained model suggested the model as invariant. Thus researchers assessed the moderating impact with different path levels. While imposing a constrained to the relationships of EO and growth the model was obtained a significant path different at 99 percent confidence levels. Thus the researchers affirmed that the model is moderated by the dimension of uncertainty avoidance with the negligible impact of the standardized beta coefficient and thus $\mathrm{H}_{2 b}$ was accepted.

\section{Moderation effect of individualism}

When considering the hypothesis of the study, the standardized beta coefficient of the relationship of EO and growth was set as 0.32 . However, the assessment of the moderation effect was caused to reduce the beta by $1 \%$ and the moderated model suggest the beta value as 0.31 . Which confirms the hypothesis of EO growth relationship is reduced or weakened in an individual culture.

When considering the statistical nature of this model the chi-square difference text was confirmed that the model as invariant. Thus researchers assessed the moderating impact with different path levels. While imposing a constrained to the relationships of EO and growth the model was obtained a significant path different at 99 percent confidence levels. Thus the researchers affirmed that the model is moderated and it weakened the relationship of EO and growth when the society holds individualism characteristics. Finally, the hypothesis $\mathrm{H}_{2 \mathrm{c}}$ was accepted.

\section{Moderation effects of assertive (masculine) and long term orientations}

These final two dimensions were not associated with significant results as intended. It was hypothesized that EO and entrepreneurial venture growth relationship is stronger in low assertive (masculine) cultures $\left(\mathrm{H}_{2 \mathrm{~d}}\right)$ and $\mathrm{EO}$ and entrepreneurial venture growth relationship is stronger in high long term oriented cultures $\left(\mathrm{H}_{2 \mathrm{e}}\right)$ but the analysis suggested that these two cultural dimensions were not act as moderators and thus these two hypothesis were rejected.

\section{Conclusions}

Findings of the current study consistent with Moreno and Casillas and relived that EO (i.e., innovativeness, risk taking behavior, proactiveness, competitive aggressiveness and autonomy) acts as an antecedent of firm growth with a positive relationship, this positive relationship has suggested by many of the authors also, the current study found out that autonomy as a dimension is not a significant predictor of EO and this remark consistent with Hughes and Morgan.

Nonetheless, relying on the main relationship of the study it does not demonstrate a complete picture of venture growth. An enhanced understanding of venture growth is proposed by the impact of innate culture of the entrepreneur despite other considerations of growth. Provided the cultural inheritance of the entrepreneur and the venture it pose important implications in executing the entrepreneurial strategy (i.e., EO) in attaining growth potentials. This premise can be attributed to the inference of 'the strength of EO-performance relationship varies across the context studied' therefore the current study suggest the variedness based on the cultural inheritance.
Complementing the remarks of the current study assessed the impact of national culture on the EO-performance relationship and important implications were derived. Mainly the study assumed that entrepreneur's willingness to take an initiative (i.e., the degree of risk assumed, innovations, entrepreneurial opportunity seeking, competitiveness and independence) is at least or partially depends on the innate culture of him/her. It was found out that the degree of dependence of employees (i.e., power distance) affects the effective utilization of entrepreneurial strategy (i.e., EO). Explaining further, when employees are closely associated with the owner of the firm EO and growth relationship gets strengthen, Researchers state that this relationship between employees and the owner of the firm is an important consideration provided that this nature creates collective setting and thus affects overall performance of the firm. As, Van Everdingen and Waarts suggested, a close relationship between employees and the owner allows owners to identify operational problems and thus affects innovation and proactive behaviors of the firm. All in overall, the study suggests the need of practicing strategies such as delegation of authority up to a certain level as it reduces the distance between employees and owners of the firm and thus facilitates EO and growth potentials of the firm.

If members of the firm threatened by inherent ambiguities and complexities in firm dealings, EO and growth relationship is weakened. This is referred to as high uncertainty avoidance and thus firm members tend to establish standardized procedures and rule as they think those brings stability to the firm. Provided that, researchers of the current study highlights organic structures as facilitators of entrepreneurial behavior. Organic structures are flexible structures which stimulates entrepreneurial behaviors and growth potentials and it does not acknowledges standardization and strict rules. Similarly, Shane claimed innovativeness associates with low uncertainty avoidance structures while, Thomas and Mueller [49], claimed low uncertainty avoidance closely associate with broad-minded people and suggesting the relationship with performance outcomes, and wrote high uncertainty avoidance and performance have a negative relationship. Therefore, the current study consistent with them and confirm that EO-growth relationship is weaken in high uncertainty avoidance structures.

Finally, the study found that EO-growth relationship is weakened in individual cultures. As this dimension refers to the independence of members of the organization it was confirmed that low in-group collectivism (usually referred to as I mentality) hinders EO-growth potentials. Therefore, the study's conclusions consistent with Hofstede and Wedel remarks and state that low in-group collectivism stimulates entrepreneurial behavior. However, this dimension is addressed and concluded differently in the literature. For example, Van Everdingen and Waarts suggested that, collectivism hinders EO-performance relationship while proposed the other way around. But the current study found consistent results to Saeed. Current study hypothesized that collective cultures facilitates effective decisions in acquiring growth potentials of the firms though Van Everdingen and Waarts claimed collective cultures slower the process. However, based on results of the study, researchers state that, as the term implies 'individualism' accepts the mentality of "I" and thus hinders EOgrowth potential.

\section{Practical and Research Implications}

Remaining entrepreneurial is vital regardless of the size of the firm. This entrepreneurial behavior requires different aspects to practice and 
entrepreneurial strategy is one of them. Theoretically entrepreneurial strategy refers to EO and it is addressed as a five dimensional framework as Lumpkin and Dess proposed. This study found out that autonomy as a dimension held insignificant when assessing growth of the firm and this was consistent with Hughes and Morgan. Therefore, it is proposed to assess the five dimensional framework of EO to assess the validity of autonomy dimension. Also the current study confirmed that EO's strength it changed along with the context, and it is partially as a cause of the innate culture of the entrepreneur. It is important to assess the cultural dimension on the relationship of EO and growth. Empirical investigations are required further to develop and advance EO literature incorporating the cultural assessment.

\section{References}

1. Shepherd D, Wiklund J (2009) Are we comparing apples with apples or apples with oranges? Appropriateness of knowledge accumulation across growth studies. Entrepreneurship, theory and practice 33: 105-124.

2. Chirico F, Sirmon DG, Sciascia S, Mazzola P (2011) Resource orchestration in family firms: investigating how entrepreneurial orientation, generational involvement, and participative strategy affect performance. Strategic Entrepreneurship Journal 5: 307-326.

3. Wales WJ, Gupta VK Mousa FT (2011) Empirical research on entrepreneurial orientation: An assessment and suggestions for future research. International Small Business Journal.

4. Saeed S, Yousafzai SY, Engelen A (2014) On cultural and macroeconomic contingencies of the entrepreneurial orientation-performance relationship. Entrepreneurship Theory and Practice 38: 255-290.

5. Rauch A, Wiklund J, Lumpkin GT, Frese M (2009) Entrepreneurial orientation and business performance: An assessment of past research and suggestions for the future. Entrepreneurship Theory and Practice 33: 761-787.

6. Miller D (1983) The correlates of entrepreneurship in three types of firms. Management Science 29: 770-791.

7. Lumpkin GT Dess GG (1996) Clarifying the entrepreneurial orientation construct and linking it to performance. Academy of Management Review 21: 135-172.

8. Covin JG and Slevin DP (1989) Strategic management of small firms in hostile and benign environments. Strategic Management Journal 10: 75.

9. Covin JG, Slevin DP (1991) A conceptual model of entrepreneurship as firm Behavior". Entrepreneurship Theory and Practice 16: 7-25.

10. Hughes M, Morgan RE (2007) Deconstructing the relationship between entrepreneurial orientation and business performance at the embryonic stage of firm growth. Industrial Marketing Management 36: 651-661.

11. Moreno AM and Casillas JC (2008) Entrepreneurial orientation and growth of smes: A causal model. Entrepreneurship Theory and Practice 32: 507-528.

12. Zahra SA, Covin JG (1995) Contextual influences on the corporate entrepreneurship-performance relationship: A longitudinal analysis. Journal of Business Venturing 10: 43-58.

13. Zahra SA (1991) Predictors and financial outcomes of corporate entrepreneurship: An explorative study. Journal of Business Venturing 6 259-285.

14. Wiklund J (1999) The sustainability of the entrepreneurial orientationperformance relationship. Entrepreneurship Theory and Practice 24: $37-48$.

15. Wiklund J, Shepherd D (2005) Entrepreneurial orientation and small business performance a configurational approach. Journal of Business Venturing 20: 71-91.

16. Morgan RE Strong CA (2003) Business performance and dimensions of strategic orientation. Journal of Business Research 56: 163-176.

17. Cassia L, Minola T (2012) Hyper-growth of smes: Toward a reconciliation of entrepreneurial orientation and strategic resources. International Journal of Entrepreneurial Behaviour and Research 18: 179-197.
18. Shane S, Venkataraman S (2000) The promise of entrepreneurship as a field of research. Academy of Management Review 25: 217-226.

19. Hayton JC, George G, Zahra SA (2002) National culture and entrepreneurship: a review of behavioral research. Entrepreneurship Theory and Practice 26: 33-52.

20. Davidsson P (1995) Culture, structure and regional levels of entrepreneurship. Entrepreneurship and Regional Development 74: 1-62.

21. Davidsson P, Wiklund J (1997) Values, beliefs and regional variations in new firm formation rates. Journal of Economic Psychology 18: 179-199.

22. Morris MH, Davis DL, Allen JW (1994) Fostering corporate entrepreneurship: cross-cultural comparisons of the importance of individualism versus collectivism. Journal of International Business Studies 2: 65-89.

23. Hofstede G (1980) Culture's Consequences: International Differences in Work-Related Values.

24. Busenitz LW, Gomez C, Spencer JW (2000) Country institutional profiles: Unlocking entrepreneurial phenomena. Academy of Management Journal 43: 994-1003.

25. Hofstede G (2001) Culture's Consequences: Comparing Values, Behaviors, Institutions, and Organizations Across Nations, (2nd edn.), Thousand Oaks: CA: Sage Publications pp: 596.

26. Van Everdingen YM, Waarts E (2003) The effect of national culture on the adoption of innovations. Marketing Letters 14: 217-232.

27. De Clercq D, Dimov D, Thongpapanl N (2010) The moderating impact of internal social exchange processes on the entrepreneurial orientationperformance relationship. Journal of Business Venturing 25: 87-103.

28. Kreiser PM, Marino LD, Dickson P, Weaver KM (2010) Cultural influences on entrepreneurial orientation: The impact of national culture on risk taking and proactiveness in SMEs. Entrepreneurship Theory and Practice 34: 959-983.

29. Shane S (1994) Cultural values and the championing process Entrepreneurship Theory and Practice18: 25-42.

30. Hofstede F, Wedel M (1999) A cross-national investigation into the individual and national cultural antecedents of consumer innovativeness. The Journal of Marketing 63: 55-69.

31. Hofstede G (1993) Cultural constraints in management theories. Academy of Management Perspectives, V. 7: 81-94.

32. Zahra SA, Hayton JC, Salvato C (2004) Entrepreneurship in family vs. Non-family firms: A resource-based analysis of the effect of organizational culture. Entrepreneurship Theory and Practice 28: 363-379.

33. Zahra SA (1996) Goverance, ownership, and corporate entrepreneurship: The moderating impact of industry technological opportunities. Academy of Management Journal 39: 1713-1735.

34. Pieris GL (2002) Task Force for SME Sector Program, National Strategy for Small and Medium Enterprise Sector Development in Sri Lanka, Colombo.

35. Delmar F (2006) Measuring growth: methodological considerations and empirical results. In Entrepreneurship and the Growth of Firms pp: 62-84.

36. Chandler GN, Hanks SH (1993) Measuring the performance of emerging businesses: A validation study. Journal of Business Venturing 8: 391- 408.

37. Brush CG, Vanderwerf PA (1992) A comparison of methods and sources for obtaining estimates of new venture performance. Journal of Business Venturing 7: 157-170.

38. Tsai WMH, Macmillan IC, Low MB (1991) Effects of strategy and environment on corporate venture success in industrial markets. Journal of Business Venturing 6: 9-28.

39. Wiklund J, Patzelt H, Shepherd D (2009) Building an integrative model of small business growth. Small Business Economics 32: 351-374.

40. Anderson JC, Gerbing DW (1988) Structural equation modeling in practice: A review and recommended two-step approach. Psychological Bulletin 103: 411-423. 
Citation: Dissanayake DM, Semasinghe DM (2016) Entrepreneurial Orientation and Growth: The Moderating Role of National Culture. J Entrepren Organiz Manag 5: 168. doi:10.4172/ 2169-026X.1000168

Page 9 of 9

41. Hooper D, Coughlan J, Mullen MR (2008) Structural equation modelling: Guidelines for determining model fit. Electronic Journal of Business Research Methods 6: 53-60.

42. Byrne BM (2010) Structural Equation Modeling with AMOS: Basic Concepts, Applications, and Programming, Taylor and Francis Group, New York.

43. James LR, Brett JM (1984) Mediators, moderators, and tests for mediation. Journal of Applied Psychology 69: 307-321.

44. Frazier PA, Tix AP, Barron KE (2004) Testing moderator and mediator effects in counseling psychology research. Journal of Counseling Psychology 51: 157-157.

45. Wang CL (2008) Entrepreneurial orientation, learning orientation, and firm performance. Entrepreneurship Theory and Practice 32: 635-656.
46. Kline RB (2011) Principles and practice of structural equation modeling. The Guilford Press, New York.

47. Brown TA (2006) Confirmatory Factor Analysis for Applied Research. The Guilford Press, New York.

48. Baron RM, Kenny DA (1986) The moderator-mediator variable distinction in social psychological research: conceptual, strategic, and statistical considerations. Journal of personality and social psychology 5 : 1173-1182

49. Thomas AS, Mueller SL (2000) A case for comparative entrepreneurship: assessing the relevance of culture. Journal of International Business Studies 31: 287-301 